\title{
Construction of Genetic Linkage Map and QTL Analysis of Sink-Size Traits in Pearl Millet (Pennisetum glaucum)
}

\author{
V. Vengadessan, ${ }^{1}$ K. N. Rai, ${ }^{2}$ J. R. Kannan Bapu, ${ }^{3}$ C. T. Hash, ${ }^{4}$ R. Bhattacharjee, ${ }^{5}$ \\ S. Senthilvel, ${ }^{6}$ M. T. Vinayan, ${ }^{7}$ and T. Nepolean ${ }^{8}$ \\ ${ }^{1}$ Pandit Jawaharlal Nehru College of Agriculture and Research Institute, Karaikal, Pondicherry 609 603, India \\ ${ }^{2}$ International Crops Research Institute for the Semi-Arid Tropics (ICRISAT), Patancheru, Andhra Pradesh 502 324, India \\ ${ }^{3}$ Tamil Nadu Agricultural University, Coimbatore, Tamil Nadu 641 003, India \\ ${ }^{4}$ ICRISAT Sahelian Center, BP 12404, Niamey, Niger \\ ${ }^{5}$ International Institute of Tropical Agriculture, PMB 5320, Ibadan, Oyo State, Nigeria \\ ${ }^{6}$ Directorate of Oilseeds Research, Indian Council of Agricultural Research, Hyderabad, Andhra Pradesh 500 030, India \\ ${ }^{7}$ International Maize and Wheat Improvement Center, ICRISAT, Patancheru, Andhra Pradesh 502 324, India \\ ${ }^{8}$ Indian Agriculture Research Institute, New Delhi 10 012, India
}

Correspondence should be addressed to V. Vengadessan; vengadessan@gmail.com

Received 27 August 2013; Accepted 4 November 2013

Academic Editors: M. Falk, J. Leips, and D. G. Peterson

Copyright (c) 2013 V. Vengadessan et al. This is an open access article distributed under the Creative Commons Attribution License, which permits unrestricted use, distribution, and reproduction in any medium, provided the original work is properly cited.

\begin{abstract}
A linkage map, primarily based on SSCP-SNP markers, was constructed using $188 \mathrm{~F}_{2: 3}$ mapping population progenies produced from a cross between two pearl millet inbred lines having diverse parentage. The skeleton linkage map covered $1019 \mathrm{cM}$ and it comprised of 44 markers distributed across the seven linkage groups. Average adjacent-marker intervals ranged from $14 \mathrm{cM}$ on LG1 to $38 \mathrm{cM}$ on LG6, with an overall mean of $23 \mathrm{cM}$. Using the $\mathrm{F}_{2}$ linkage map and phenotypic data from the $\mathrm{F}_{2}$ and $\mathrm{F}_{2: 3}$ generations of the mapping population, a total of 18 putative QTLs were detected for the three sink-size components. Eight QTLs explained 42.7\% of observed phenotypic variation for panicle length using the $\mathrm{F}_{2.3}$ data set. For panicle diameter, 5 QTLs explained $45.8 \%$ of observed phenotypic variation. Similarly for grain size, 5 QTLs explained $29.6 \%$ of phenotypic variation. Genomic regions associated with panicle length, panicle diameter, and grain size were comapped on LG6 between Xpsms88 and Xpsms2270, indicating the existence of a gene or gene cluster. The QTLs for panicle length on LG2 and LG6 (LOD > 3 in both $\mathrm{F}_{2}$ and $\mathrm{F}_{2: 3}$ data sets), for panicle diameter on LG2 and LG3 (LOD > 14 in the $\mathrm{F}_{2: 3}$ data set), and for grain size on LG3 and LG6 (LOD > 3 in both $\mathrm{F}_{2}$ and $\mathrm{F}_{2: 3}$ data sets) were identified as promising candidates for validation prior to possible application in marker-assisted breeding.
\end{abstract}

\section{Introduction}

Pearl millet (Pennisetum glaucum (L.) R. Br., $2 n=2 x=$ 14 ) is a major cereal crop grown in the arid and semiarid tropical regions of Asia and Africa. It produces grains with high nutritive value even under hot, dry conditions, on infertile soils of low water holding capacity, where other cereal crops fail. This makes pearl millet a highly desirable crop for farmers in such harsh environments. Largely because of these harsh environments in which most of the pearl millet is grown, its average grain yield in Africa and Asia fluctuates between 500 and $600 \mathrm{~kg} \mathrm{ha}^{-1}$, which is extremely low compared to other cereal crops grown in more favorable environments. Grain yield stabilization and improvement are of primary importance in pearl millet breeding programs. Grain yield is a function of total dry matter yield and harvest index, and enhancing the total dry matter yield and harvest index or both can increase grain yield. In general, harvest index can be increased by improving sink size and it has been demonstrated in many correlation studies that traits such as panicle size (length and diameter) and grain size have direct positive correlations with grain yield $[1,2]$. Hence, enhancement of these sink-size component traits is an important objective in pearl millet breeding. Importance 
of sink-size traits as major selection criteria for improving grain yield has been emphasized in many studies. However, in pearl millet poor sink capacity with low harvest index (15-20\%), which in turn leads to low grain yield, has been considered basic problems of the species itself [3]. Further, selection for individual sink-size traits has not always produced the desired yield gains. For instance, three cycles of mass selection for increased panicle, grain size, and grain yield of pearl millet produced inconsistent responses [4]. The poor response of these traits to such simple selection procedures might be due to the complex inheritance and compensatory association among these traits, as well as the low heritability of individual plant performance and lack of control on genetic contributions of the male parents to the seed harvested following postflowering mass selection.

In recent years, quantitative traits locus (QTL) analysis has become a key tool for dissecting the genetic architecture of complex quantitative traits into their component loci, facilitating estimation of the minimum number of genomic regions that affect a trait (and its components), the distribution of gene effects, and the relative importance of additive, dominant, and epistatic gene action. QTL analysis not only identifies the presence of putative QTLs but also can also provide appropriate targets for further marker-assisted crop improvement $[5,6]$. However, effective and accurate detection of QTLs requires a genetic map providing at least "skeleton coverage" with one marker every 10-20 cM across the entire nuclear genome or at least that portion of it for which the mapping population parents do not share common alleles for target traits of interest. This, in turn, requires an appropriate mapping population. In pearl millet, several $\mathrm{F}_{2: 3}$ and $\mathrm{F}_{2: 4}$ mapping populations have been developed from diverse inbred lines of Asian, American, and African origin [7] and genomic positions of QTLs were mapped for disease resistance [8-14], abiotic stress tolerance [6, 10, 15$18]$, phenology $[19,20]$, grain and stover yield, and quality components [16, 18, 20-23]. However, panicle and grain size, though being major determinants of grain yield in pearl millet, have been sparingly subjected to QTL analysis.

Genetic linkage maps are constructed based on different kinds of populations [24], with each population structure having unique strengths and weaknesses. Large $\mathrm{F}_{2}$ mapping populations can be generated quickly, which harbor many of the possible combinations of parental alleles [25]. However, for quantitative traits with low heritability, the precision of QTL mapping with an $\mathrm{F}_{2}$ population may be relatively poor. To solve these problems, each $\mathrm{F}_{2}$ individual can be selfpollinated, the resulting seed can be sown as $F_{3}$ progeny in replicated progeny trials, and the family means, across replications can be used as phenotypic values in the genetic analysis $[26,27]$. This is referred to as a replicated $\mathrm{F}_{2: 3}$ design in plant genetics [28]. In QTL analysis, the method for a $\mathrm{F}_{2: 3}$ design is adopted by simply replacing the individual $\mathrm{F}_{2}$ phenotype with the average value of its corresponding $\mathrm{F}_{2: 3}$ progeny [29].

Several marker systems have been used to develop genetic linkage maps in pearl millet. These include RFLPs $[6,8$, $9,11,12,16-20,30-34]$ and SSRs [14, 33-35]. SSRs present in ESTs are referred to as EST-SSRs, and are abundant in such EST sequences. The development of SSRs based on EST sequences is a fast, efficient, and economic option [35-38]. In addition, a new generation of marker system termed single-strand conformational polymorphism-single nucleotide polymorphism (SSCP-SNP) has been developed in pearl millet to take advantage of the SSCP technique and the large number of SNPs in the nonexpressed intron regions of genes [39], which are also the target of the conserved intron-spanning primer (CISP) markers [40]. SNP markers provide an inexhaustible source of polymorphic markers for use in high-resolution genetic mapping and are the most abundant type of molecular genetic markers in the genome.

In the present study, we developed a new pearl millet genetic linkage map primarily based on SSCP-SNP markers and used this map for QTL analysis of sink-size traits using phenotypic data of the unreplicated $\mathrm{F}_{2}$ population and replicated $\mathrm{F}_{2: 3}$ mapping progenies derived from a cross of two inbred lines having large differences in sink-size traits (panicle size and grain size).

\section{Materials and Methods}

2.1. Plant Material and Field Experiment. The mapping population, consisting of $188 \mathrm{~F}_{2}$ individuals and their $\mathrm{F}_{2: 3}\left(\mathrm{~F}_{2}\right.$ derived $\mathrm{F}_{3}$ ) progenies, was produced from a cross between two diverse inbred lines: $(81 \mathrm{~B} \times 4025-3-2-\mathrm{B})-11-5-2-2-\mathrm{B}-2$ used as the female parent and hereafter referred to as $\mathrm{P}_{1}$ and HHVBC II D2 HS-302-3-1-6-8-2-6-2-B used as male parent and hereafter referred to as $\mathrm{P}_{2}$. These lines differed primarily for grain size ( $5 \mathrm{~g} 1000$-grain female parent versus $13 \mathrm{~g}$ 1000-grain male parent) and panicle diameter (16 mm female parent versus $38 \mathrm{~mm}$ male parent). They also differed for panicle length $(29 \mathrm{~cm}$ female parent versus $24 \mathrm{~cm}$ male parent). The $\mathrm{F}_{1}$ seeds, produced by crossing $\mathrm{P}_{1}$ and $\mathrm{P}_{2}$ lines during 2005-06 postrainy season (Dec.-Feb.), were planted in greenhouse condition and then self-pollinated to produce $\mathrm{F}_{2} \mathrm{~s}$ during Mar.-Jun. 2006. In 2006 rainy season (Jun.-Sep.), a random sample of $F_{2}$ seeds was taken from the $F_{1}$ panicle, was sown in a 20 -rows plot, along with 2 -row plots of both parental inbred, and phenotypic observations were made on $188 \mathrm{~F}_{2}$ plants, selected randomly. These $\mathrm{F}_{2} \mathrm{~s}$ in turn were selfpollinated to produce $\mathrm{F}_{2: 3}$ progenies. In 2007 summer season (Jan.-Apr.), each of the $188 \mathrm{~F}_{2: 3}$ progenies and their parental lines were raised as single-row plots in a partial lattice $(\alpha$ design) with three replications for phenotypic evaluation of sink-size traits. In both seasons, phenotyping experiments were conducted in Alfisols at the ICRISAT, Patancheru, and the rows were $4 \mathrm{~m}$ long and $60 \mathrm{~cm}$ apart, and seeds were hand dibbled into hills at a spacing of $20 \mathrm{~cm}$ within each row, and each hill was thinned to a single plant about 2 weeks after crop emergence. Observations were recorded on sink-size traits such as panicle length $(\mathrm{cm})$, panicle diameter $(\mathrm{mm})$, and grain size (g/1000 grains, determined from a sundried random sample of 200 grains) on the main-stem panicles of 188 individual selfed $\mathrm{F}_{2}$ plants and 20 plants for each of the parental inbreds; while in the replicated $\mathrm{F}_{2: 3}$ mapping population progenies trial, observations were recorded for these traits on 10 random open-pollinated plants in each plot. 
TABle 1: Polymorphism detected between the parental inbred pair by different pearl millet marker types.

\begin{tabular}{lcccc}
\hline Marker types & Number tested & $\begin{array}{c}\text { Number of } \\
\text { polymorphic } \\
\text { markers detected }\end{array}$ & Percent polymorphism & $\begin{array}{c}\text { Number of polymorphic } \\
\text { markers } \\
\text { selected for skeleton map }\end{array}$ \\
\hline SNP & 96 & 40 & 42 & 24 \\
SSR & 96 & 36 & 38 & 10 \\
EST-SSR & 96 & 28 & 29 & 6 \\
STS & 43 & 5 & 12 & 4 \\
\hline Total & 331 & 109 & 33.0 & 44 \\
\hline
\end{tabular}

2.2. DNA Extraction and Marker Polymorphism. DNA extraction was done using bulk tissue samples (collected from 25-30 random seedlings) of each of $188 \mathrm{~F}_{2: 3}$ progeny (essentially representing the $\mathrm{F}_{2}$ individuals from which each family of $\mathrm{F}_{2: 3}$ progenies was derived) and their parental inbreds, following a modified CTAB method [41]. DNA quality and quantity were checked on $0.8 \%$ agarose gels and samples were normalized to approximately $2.5 \mathrm{ng} / \mu \mathrm{L}$. A total of 331 pearl millet primer pairs, which included 96 each for SSCP-SNP, SSR, and EST-SSR markers and 43 for STS markers, were initially assayed against DNA samples from the parental inbreds to identify polymorphic markers (Table 1). This resulted in identification of 109 polymorphic markers (33\%), from which a final set of 44 (24 SSCP-SNPs, 10 genomic SSRs, 6 EST-SSRs, and 4 STSs) were selected for use in skeleton mapping the population based on expected marker distribution across the genome, PCR banding pattern (at least 2 bp difference in parental allele sizes), and consistent amplification, to facilitate reliable genotyping of the mapping population progenies using polyacrylamide gel electrophoresis (PAGE) and/or capillary electrophoresis.

\subsection{Polymerase Chain Reaction (PCR) Amplification} and Marker Analysis. PCR amplification for SSCP-SNP, fluorescence-labeled SSR, EST-SSR, and STS was performed in volumes of $5 \mu \mathrm{L}$ reaction. PCRs were conducted in 96and 384-well plates using a GeneAmp PCR system PE 9700 (Applied Biosystems, USA) DNA thermocycler. A touchdown PCR program was used to amplify the DNA fragments with initial denaturation for 15 minutes at $94^{\circ} \mathrm{C}$, followed by 10 cycles of denaturation for 10 seconds at $94^{\circ} \mathrm{C}$, annealing at $61^{\circ} \mathrm{C}$ down to $52^{\circ} \mathrm{C}$ for 20 seconds (annealing temperature for each cycle was reduced by $1^{\circ} \mathrm{C}$ ), and extension at $72^{\circ} \mathrm{C}$ for 30 seconds. This was followed by 20 minutes extension at $72^{\circ} \mathrm{C}$ to ensure amplification of equal lengths of both DNA strands.

PCR products of EST-SSR and STS primer pairs were separated by nondenaturing PAGE on $8 \%$ polyacrylamide gels, while those of SSCP-SNP primer pairs were electrophoretically separated on $300 \times 380 \times 0.4 \mathrm{~mm}$ single-strand conformational polymorphism (SSCP) gels using mutation detection enhancement (MDE) gel solution [42]. The PCR products of SSCP-SNP primer pair were denatured at $94^{\circ} \mathrm{C}$ for 5 minutes then immediately cooled to $4^{\circ} \mathrm{C}$ and separated on SSCP gels by electrophoresis for $16 \mathrm{~h}$ at a constant power of
$8 \mathrm{~W}$ at room temperature. Electrophoretically separated ESTSSR, STS, and SSCP-SNP fragments were visualized using a modified silver staining procedure [43]. Dye-labeled PCR products of SSRs were separated by capillary electrophoresis using an ABI Prism 3700 automatic DNA sequencer (Applied Biosystems). PCR products were pooled post-PCR, where $1 \mu \mathrm{L}$ each of 6-FAM, 6-VIC, 6-NED, and 6-PET labeled products were mixed with $7 \mu \mathrm{L}$ of formamide (Applied Biosystems), $0.3 \mu \mathrm{L}$ of LIZ-labeled (500-250) size standard (Applied Biosystems), and $4.2 \mu \mathrm{L}$ of distilled water. The Genescan 3.1 software (PE-Applied Biosystems) was used to size the peak patterns using the internal LIZ (500-250) size standard, and Genotyper 3.1 (PE-Applied Biosystems) was used for allele calling.

2.4. Phenotypic Analysis. GenStat V.8.0 program [44] was used for the analysis of variance for the summer season $\mathrm{F}_{2: 3}$ progeny trial using the Residual Maximum Likelihood (ReML) algorithm, which provides Best Linear Unbiased Predictors (BLUPs) of the performance of each genotype under test. The BLUPs for each observed trait for the parental lines and $\mathrm{F}_{2: 3}$ mapping progenies were calculated by considering entries as fixed effects and block and entry $\times$ replication interaction as random effects. Heritability (broad sense) was estimated for each observed trait [45].

2.5. Linkage Map Construction and QTL Analysis. Marker classes at each locus were summarized for all individuals into three different genotypic classes expected for an $\mathrm{F}_{2}$ population. The segregation of each marker was tested with a $\chi^{2}$ test for goodness of fit to the expected Mendelian segregation ratio $(1: 2: 1)$. The linkage map was constructed using MAPMAKER/EXP V. 3.0 [25] and using the Haldane mapping function to convert recombination frequencies to genetic distances in centiMorgan (cM) units. The group command with a LOD score of 3.5 was used to identify linked subsets of the $\mathrm{F}_{2}$ population marker data, implementing twopoint analysis. Based on common markers, linkage group names and orientations were assigned to agree with the existing pearl millet consensus linkage map [34].

The data sets of the $188 \mathrm{~F}_{2}$ plants and the BLUPs of their $\mathrm{F}_{2: 3}$ progenies, along with the corresponding genotyping data for 44 markers, combined with the linkage map, were used to identify genomic regions associated with observed sinksize traits using composite interval mapping (CIM) analysis as implemented in PLABQTL V. 1.1 [46], which performs 
CIM using a regression approach with selected markers as cofactors. Markers to serve as cofactors were initially identified using stepwise multiple-marker regression with an Fto-enter and F-to-delete threshold value of 2.5. The presence of a putative QTL in a marker interval was tested using a critical LOD threshold determined by PLABQTL using the Bonferroni chi-square approximation corresponding to a genome-wise type I error of 0.25 [47]. As the mapping population used in the present study was phenotyped both as $\mathrm{F}_{2}$ individuals and $\mathrm{F}_{2: 3}$ progenies, the additive $(\mathrm{A})$ model along with additive + dominance $(\mathrm{A}+\mathrm{D})$ and epistatic $(\mathrm{A}+$ $\mathrm{D}+\mathrm{AA}+\mathrm{AD}+\mathrm{DD})$ genetic models were included for the analyses. All specified digenic epistatic effects were estimated by PLABQTL in the final simultaneous fit for the detected set of QTLs using a stepwise regression procedure whereby the F-to-enter value (and F-to-delete) was obtained by using the Bonferroni bound at alpha $=0.05$. Estimated genetic effects were positive if the male parent allele contributed positively to the trait of interest and negative if female parent allele contributed positively towards the trait of interest. Note that as the $\mathrm{F}_{2}$ model was applied for the QTL analysis, the dominance (D) effects estimated for the $\mathrm{F}_{2: 3}$ data sets were underestimated (those observed in the $\mathrm{F}_{3}$ generation are expect to be half those of their comparable $\mathrm{F}_{2}$ data set), so the $\mathrm{F}_{2: 3}$ adjusted $R^{2}$ values are crude estimates as being the estimates of epistatic effects.

\section{Results and Discussion}

3.1. Genetic Linkage Map Construction. Identification of sufficient number of markers revealing polymorphism among parental lines is a prerequisite for the construction of a genetic linkage map. In the present study, the mapping population was based on a pair of genetically diverse inbred lines, for which a high number of polymorphic markers (109) with wide genome coverage were identified. The large genetic distance between the parental lines of the mapping population in the present study provided a high degree of polymorphism for markers across most of the linkage groups (Table 1). Among the 331 markers assayed (96 each of SSCP-SNP, SSR, and ESTSSR and 43 STS) on parental lines for polymorphism in the present study, SSCP-SNP markers showed the highest level of polymorphism (42\%), followed by genomic SSRs (38\%), EST-SSRs (29\%), and STS markers (12\%). This finding is at variance to the report of Bertin et al. [39] who observed lower polymorphism for SSCP-SNPs than the genomic SSRs, as evident from the reported mean PIC values of 0.49 for SSCPSNP and 0.72 for genomic SSR markers tested on a common genotypic panel of pearl millet inbreds. However, Rafalski [48] reported $86 \%$ SNP polymorphism in maize inbreds and found that the frequency of nucleotide change among inbreds was high, at around one in every $48 \mathrm{bp}$ in noncoding regions and one in every $130 \mathrm{bp}$ in coding regions. SNPs are reported as an essentially inexhaustible source of polymorphic markers for use in high-resolution genetic mapping. SNP markers also have great advantages in unraveling detailed syntenic relationships in specific parts of the genome in comparative mapping applications [48]. Although both genomic SSRs and
EST-SSRs showed less polymorphism than SNPs in this study, they were very informative, since they are codominant, locusspecific, and evenly distributed [49]. In pearl millet, Qi et al. [34] reported an average PIC value of 0.71 for genomic SSR markers, which suggests that microsatellite markers could be used successfully for many types of investigations. The STS marker system showed much lower polymorphism (12\%) in this present study. The low level of polymorphism of the STS marker system was observed because much of the polymorphism of the RFLP markers on which they were based can no longer be detected without the use of multiple restriction enzymes [50]. However, these markers have proven useful to cover telomeric regions of the chromosomes, where other marker systems have shown relatively poor coverage.

A set of 44 polymorphic markers well distributed across the seven pearl millet linkage groups were finally selected to genotype $188 \mathrm{~F}_{2: 3}$ mapping progenies to construct the skeleton linkage map. The larger the mapping population, the higher the confidence in the estimates of recombination frequencies, the more accurate the map distances, and the higher the chance of detecting QTLs with small effects and estimates of the gene effects [51]. However, the optimum size of mapping population depends on the genome size of the organism, the generation of mapping population, and the nature of the trait under study [52]. A population size of $188 \mathrm{~F}_{2: 3}$ progenies used in the present study appears to be reasonably large, but not too large compared to the plant numbers that have been analyzed in comparable studies [31].

Chromosomal regions that cause distorted segregation ratios may be detected by segregation distortion of mapped loci [53]. If a segregation-distorted locus (SDL) segregates in a population, markers linked to this SDL will also show distorted segregation. In the present study, only four out of 44 markers showed distorted segregation. These markers were Xicmp3063, Xpsms31, Xpsms18, and Xpsmp2027. Earlier studies also reported distorted marker segregation in pearl millet $[18,30]$. Markers that show obvious distortion are often excluded from the linkage analysis. However, this usually leads to reduction in genome coverage and detection of fewer QTLs. No attempt was made to investigate the cause of these distortions, as most distortions appear to be crossspecific. A possible mechanism suggested is that there may be a gene (or chromosomal rearrangement) present in the distorted segregation region that affects gametophytic or zygotic competitiveness [34]. For a correctly inferred marker order and map distance, influence of segregation distortion on QTL analysis should be negligible [54]. The detection of QTLs through composite interval mapping which involves stepwise regression does not get affected by segregation distortion of marker loci [55].

The selected 44 polymorphic loci to cover the entire pearl millet genome proved suitable for constructing a skeleton linkage map based on $188 \mathrm{~F}_{2: 3}$ mapping population progenies. The present map spans 1019 Haldane cM, covering all seven linkage groups with an average marker interval of $23 \mathrm{cM}$ (Table 2). The present map covering a substantially larger proportion of the pearl millet nuclear genome is comparable with earlier reported linkage maps for this species $[6,16$, 18, 32-34]. LG1, which had a length of about $110 \mathrm{cM}$, was 
TABLE 2: Distribution and distance coverage by 44 marker loci across seven pearl millet skeleton map linkage groups.

\begin{tabular}{lcccc}
\hline Linkage group & Number of markers & \% of total markers & Total map length $(\mathrm{cM})$ & Average intermarker distance $(\mathrm{cM})$ \\
\hline LG1 & 8 & 18 & 110 & 16 \\
LG2 & 8 & 18 & 195 & 28 \\
LG3 & 9 & 20 & 180 & 23 \\
LG4 & 2 & 5 & 38 & 38 \\
LG5 & 7 & 16 & 172 & 29 \\
LG6 & 6 & 14 & 228 & 46 \\
LG7 & 4 & 9 & 96 & 32 \\
\hline Total & 44 & 100 & 1019 & 23 \\
\hline
\end{tabular}

TABLE 3: Means, operational heritabilities, and correlation coefficients for pearl millet sink-size traits.

\begin{tabular}{lccccccc}
\hline \multirow{2}{*}{ Traits } & \multirow{2}{*}{ Trial } & \multicolumn{3}{c}{ Mean } & Operational heritability & \multicolumn{2}{c}{ Correlation coefficient } \\
& & $\mathrm{P}_{1}$ & $\mathrm{P}_{2}$ & $\mathrm{~F}_{2}$ or $\mathrm{F}_{2: 3}$ & & Panicle length & Panicle diameter \\
1000-grain mass
\end{tabular}

** Significant at $P<1 \%$.

comparable to the map length reported by Devos et al. [33]. The other linkage groups that were expected to provide nearly complete chromosome coverage are LG2, LG3, LG5, and LG6, which carried markers in the centromeric and distal regions. The two linkage groups that were shorter than expected are LG4 and LG7, with genetic lengths of $38 \mathrm{cM}$ and $96 \mathrm{cM}$, respectively. The unexpectedly shorter lengths of LG4 and LG7 were probably due to lack of polymorphic markers between the parents used in this study for some portions of these two linkage groups.

Broad genome coverage was achieved mainly because the relative positions of most of the markers used were already known, so those detecting loci relatively evenly distributed across both centromeric and distal regions across all seven linkage groups were chosen for use. The percentage of markers assigned to the five linkage groups (having good coverage in this study) is in good agreement with estimates obtained by other researchers $[18,33]$. The number of markers assigned to each linkage group and their map distances is in part a reflection of the relative amount of genetic variation present among the linkage groups. The present map (like other pearl millet maps) had large gaps in the distal regions, for which the most probable reason could be that recombination is extremely localized in the distal regions of chromosomes in pearl millet [34]. It is, however, possible that pearl millet linkage maps are still incomplete and genomic sequences of rice and sorghum could be used to develop new markers that could be mapped on distal regions of pearl millet linkage groups. This will, of course, require that colinearity between rice, sorghum, and pearl millet is maintained in these distal chromosomal regions $[33,34]$.
3.2. Phenotypic Analysis. Phenotypic characterization of quantitative traits is a prerequisite to the application of molecular genetic knowledge for broadening our understanding of their genetic control. The mean, broad-sense heritability, and correlation coefficient estimates for the observed traits are presented in Table 3. The analysis of variance for the replicated phenotypic data from the $\mathrm{F}_{2: 3}$ trial showed that variances due to $F_{2: 3}$ progenies were highly significant for all the three traits. The mean performance of the parents displayed substantial differences for these traits. The reliability of QTL mapping also largely depends upon the heritability of individual traits [56]. High broad-sense heritability estimates were obtained for panicle length (0.71) and panicle diameter $(0.72)$ in the $F_{2}$ population. However, the heritability estimate for grain size was moderate (0.59). For the $\mathrm{F}_{2: 3}$ progenies, the heritability estimates were high for all observed traits ranging between 0.81 and 0.91 . Heritability estimates (board-sense) in the $F_{2}$ population and from the replicated evaluation of the $\mathrm{F}_{2: 3}$ progeny population for all the three observed traits were greater than $50 \%$, which is a prerequisite for effective QTL mapping. As expected, the heritability estimates from the replicated $\mathrm{F}_{2: 3}$ progenies were higher than those from the $\mathrm{F}_{2}$ population.

Knowledge of correlations among the observed traits gives an idea about changes brought about by selection that simultaneously influences correlated traits [57] and also indicates the chances of identifying comapped QTLs for the correlated traits. In the $\mathrm{F}_{2}$ population, correlations among the three sink-size traits were found to be nonsignificant. However, in the $\mathrm{F}_{2: 3}$ progenies, panicle length had a significant negative though low correlation with panicle diameter $(r=$ 
$-0.30)$, while panicle diameter had a significant positive and moderate correlation with grain size $(r=0.55)$. These results indicate that by carefully selecting parental alleles associated with increasing or decreasing combinations of traits, it should be possible to improve the traits simultaneously.

The frequency distribution of panicle length in the $F_{2}$ population showed a bimodal distribution, whereas the $\mathrm{F}_{2: 3}$ progenies showed a continuous symmetrical distribution (Figure 1). For panicle diameter an irregular distribution was observed in the $\mathrm{F}_{2}$ population; however, among the $\mathrm{F}_{2: 3}$ progenies, it showed a symmetrical distribution. Grain size (1000-grain mass) represented a continuous symmetrical distribution in both $\mathrm{F}_{2}$ and $\mathrm{F}_{2: 3}$ mapping populations. Continuous distribution or absence of discrete segregating classes for a trait suggests that its inheritance is either determined by a large number of genes with small effects or a few major genes with substantial environmental effects. Transgressive segregants were observed for panicle length. The presence of transgressive segregants suggested that the two parental lines each had desirable and undesirable alleles in various proportions for loci governing this trait. For both panicle diameter and grain size transgressive segregants were not observed either in $\mathrm{F}_{2}$ or in $\mathrm{F}_{2: 3}$ progeny populations, indicating that all the alleles with positive effect for both traits were in one parent and those with negative effects in the other parent.

\subsection{Mapping QTLs for Sink-Size Traits}

3.3.1. Panicle Length. QTLs identified for panicle length using three genetic models are presented in Table 4 . The additive genetic model identified seven QTLs, one each on LG1, LG2, LG3, LG4, and LG7 and two on LG6 using $\mathrm{F}_{2: 3}$ progeny data for this trait. The LOD scores for these QTLs ranged from 2.9 to 8.0 , and the portion of observed phenotypic variation explained by these individual QTLs due to their additive effects ranged from 6.8 to $25.9 \%$. The favorable alleles for the QTLs on LG1, LG2, LG6, and LG7 were from $\mathrm{P}_{1}$, while for the QTLs on LG3 and LG4, the positive effects were from $\mathrm{P}_{2}$. The total variation explained by the additive model was $40.7 \%$. This model failed to detect any QTLs for panicle length using $\mathrm{F}_{2}$ of the data set. The additivedominance model identified eight QTLs for panicle length using the $\mathrm{F}_{2: 3}$ data set, one each on LG1, LG2, LG4, and LG7 and two each on LG3 and LG6. The LOD scores for these QTLs individually ranged from 2.6 to 8.2 and explained 5 to $27 \%$ of additive effects for the observed phenotypic variation among the $\mathrm{F}_{2: 3}$ progenies, while the dominance effects explained 0 to $1.4 \%$ of this variation. Panicle length QTLs on LG3 and LG4 had favorable alleles from $\mathrm{P}_{2}$, while for the remaining QTLs favorable alleles were from $\mathrm{P}_{1}$. In the $\mathrm{F}_{2}$ population, two QTLs on LG2 and LG6 were detected with LOD values of 3.3 and 3.7, respectively, with additive effects explaining 0.5 and $3.4 \%$ of observed phenotypic variation and their dominance effects explaining $0.7 \%$ and $3.4 \%$ of this variation, respectively. The total variation explained by the additive + dominance model was $42.7 \%$ in the $\mathrm{F}_{2: 3}$ data set and $13.1 \%$ in the $\mathrm{F}_{2}$ data set. The epistatic model detected four significant QTL pair interactions (2 additive $\times$ additive and 2 dominance $\times$ dominance) for panicle length with $\mathrm{F}_{2: 3}$ data set. These pairwise epistatic interactions individually explained between 6.5 and $12.3 \%$ of observed panicle length variation. No significant epistatic interactions were detected using the $\mathrm{F}_{2}$ data set. A total of $40.1 \%$ of observed panicle variation among the $\mathrm{F}_{2: 3}$ progenies and $12.5 \%$ of variation in the $\mathrm{F}_{2}$ population were explained by this model.

Earlier QTL mapping studies examining panicle length in pearl millet have demonstrated that this trait is affected by genomic regions distributed across LG1, LG2, LG4, and LG7 $[31,32]$. In the present study, QTL analysis identified eight genomic regions, one each on LG1, LG2, LG4, and LG7 and two each on LG3 and LG6 that contributed significantly to the genetic control of panicle length. The portion of observed variation explained by the individual QTLs ranged from 6.1 to $18.2 \%$. Among the detected QTLs in the present study, the largest portion of variation (26.9\%) was explained by a QTL on LG2 (Xpsmp2237-Xpsms89) followed by a QTL on LG6 (Xpsms88-Xpsmp2270), which explained $12.8 \%$ of observed variation, with the $\mathrm{P}_{1}$ alleles at both of these QTLs increasing panicle length. The detection of more QTLs (all of small effect) in the $\mathrm{F}_{2: 3}$ progenies than the $\mathrm{F}_{2}$ population is likely the result of higher operational heritability for this trait obtained from the replicated $\mathrm{F}_{2: 3}$ progeny trials. Though significant interactions among the QTLs on LG1, LG3, LG6, and LG7 were detected using the epistatic model, the proportion of observed phenotypic variation explained by the additive + dominance model for this trait was marginally higher than the additive and epistatic model in both $\mathrm{F}_{2}$ population $(13.1 \%)$ and $\mathrm{F}_{2: 3}$ progenies $(42.7 \%)$. This suggests that the QTLs detected for panicle length in this population are mainly controlled by additive effects with no significant dominance effects detected among $\mathrm{F}_{2: 3}$ progenies and with possible modest (but significant) epistatic interactions. Alternatively, the epistatic model fails to properly account for the halving of dominance effects (compared to those expected in the $\mathrm{F}_{2}$ generation) observed using $\mathrm{F}_{3}$ progeny data; thus the results from this model should be ignored.

3.3.2. Panicle Diameter. QTLs identified for panicle diameter using three genetic models are presented in Table 5. Using the additive model, four QTLs were detected for panicle diameter on LG2, LG3, LG6, and LG7 with the $\mathrm{F}_{2: 3}$ data set. The LOD scores ranged from 3.6 to 14.7 and the portion of observed variation explained by the individual QTLs ranged between 8.9 and $28.6 \%$. The favorable alleles for all QTLs were contributed by $\mathrm{P}_{2}$. The portion of observed variation explained by the additive model was $44.3 \%$. The additive + dominance model identified five QTLs for this trait, distributed across LG2, LG3, LG5, LG6, and LG7, using the $\mathrm{F}_{2: 3}$ data set, with LOD scores ranging between 2.6 and 14.7. The portion of phenotypic variation explained by additive effects of individual QTLs ranged from 3.6 to $29.1 \%$ and that explained by dominance effects ranged between 0.1 and 2.1\% (nonsignificant). The favorable alleles for all these QTLs were contributed by $\mathrm{P}_{2}$. The QTL on LG5 exhibited recessive inheritance. The portion of observed phenotypic variation 


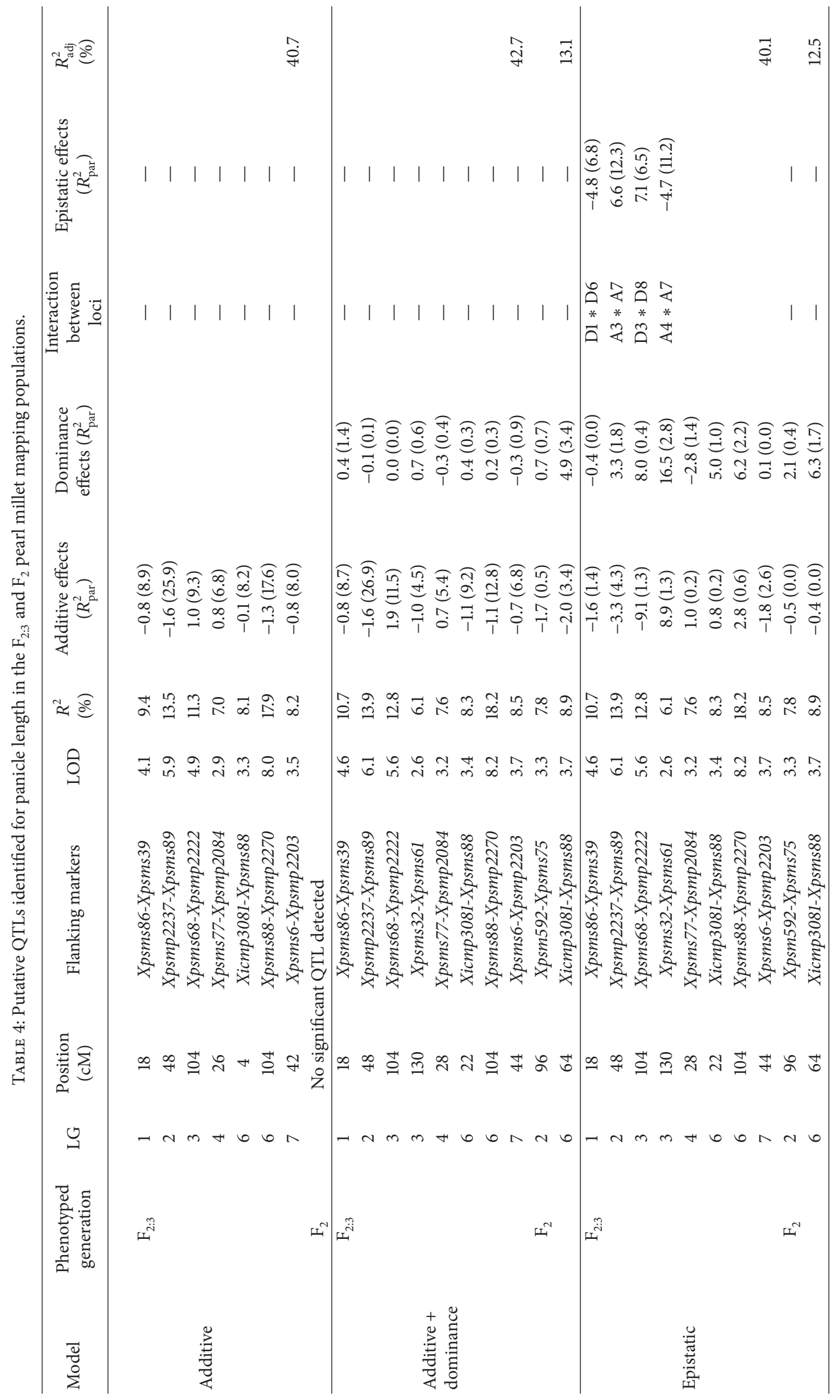



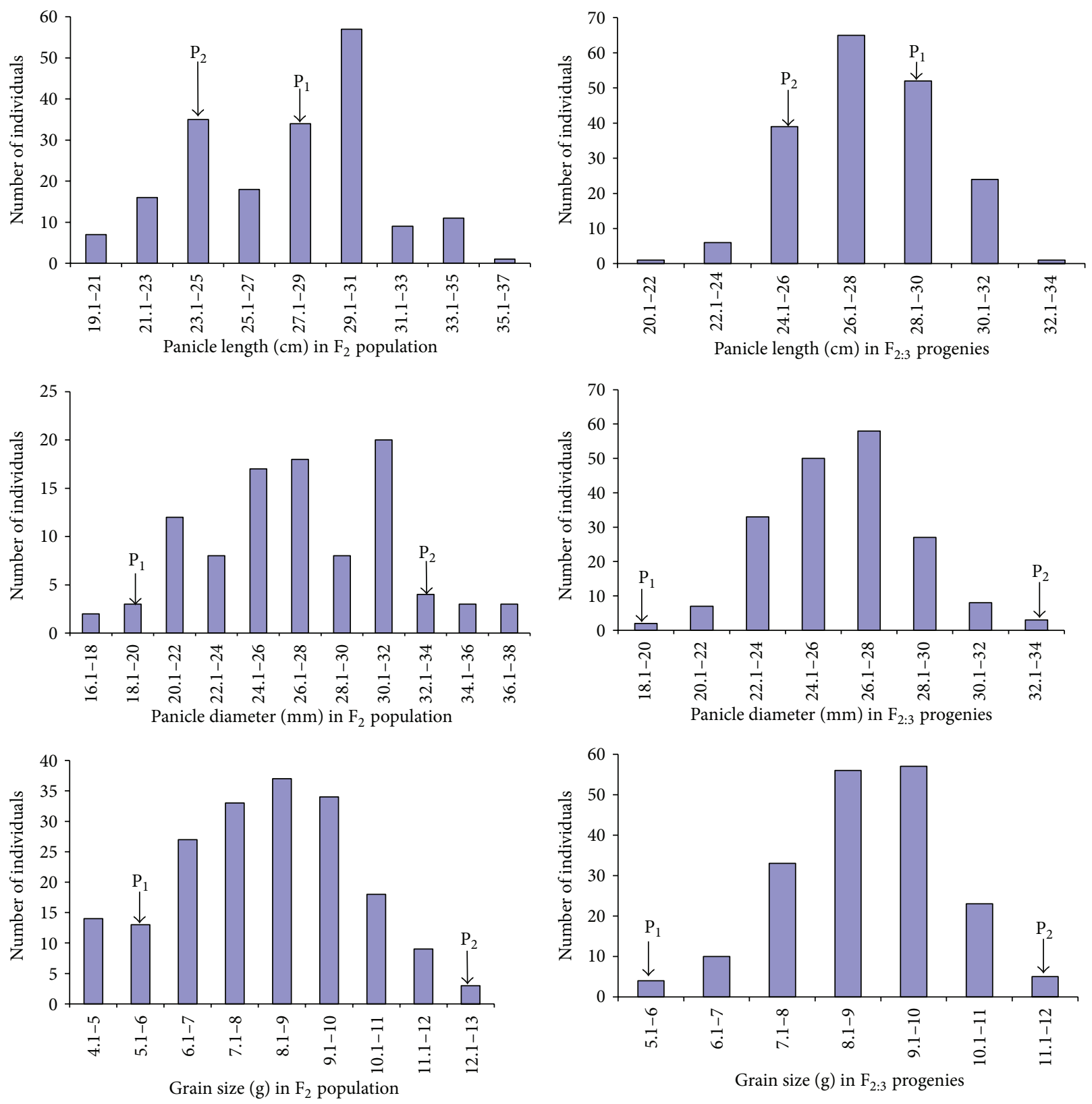

FIGURE 1: Frequency distribution for sink-size traits in the $\mathrm{F}_{2}$ and $\mathrm{F}_{2: 3}$ mapping populations of pearl millet.

explained by this model was $45.8 \%$. Using the epistatic model, the QTL on LG2 showed significant additive $\times$ dominance interaction effects with the QTL on LG3 and this pairwise interaction explained $2.8 \%$ of the observed phenotypic variation for panicle diameter. The epistatic model explained $41 \%$ of observed phenotypic variation for this trait.

Across all the genetic models, five QTLs were detected and mapped on LG2, LG3, LG5, LG6, and LG7 for panicle diameter using the $\mathrm{F}_{2: 3}$ progeny data set (Figure 2). The portion of observed variation explained by these individual QTLs ranged from 6.3 to $30.2 \%$ with LOD values of 2.6 to 14.7. For all these QTLs, favorable alleles were contributed by $\mathrm{P}_{2}$. The QTLs on LG5, LG6, and LG7 corresponds with the previous reports for QTL positions of this trait [31, 32]. However, the additional QTLs on LG2 and on LG3 had LOD scores greater than 14.0 and explained large proportions of observed phenotypic variation for this trait. A significant additive $\times$ dominance interaction was observed between the two major QTLs located on LG2 and LG3 and explained $2.8 \%$ of observed variation. The additive + dominance model explained the highest portion of observed variation (45.8\%) for this trait; however, the dominance effects of the QTLs were nonsignificant that could have likely resulted from underestimation of dominance effects using the $\mathrm{F}_{2: 3}$ data set. All three genetic models failed to detect any significant QTL(s) for panicle diameter using the $\mathrm{F}_{2}$ data set. 


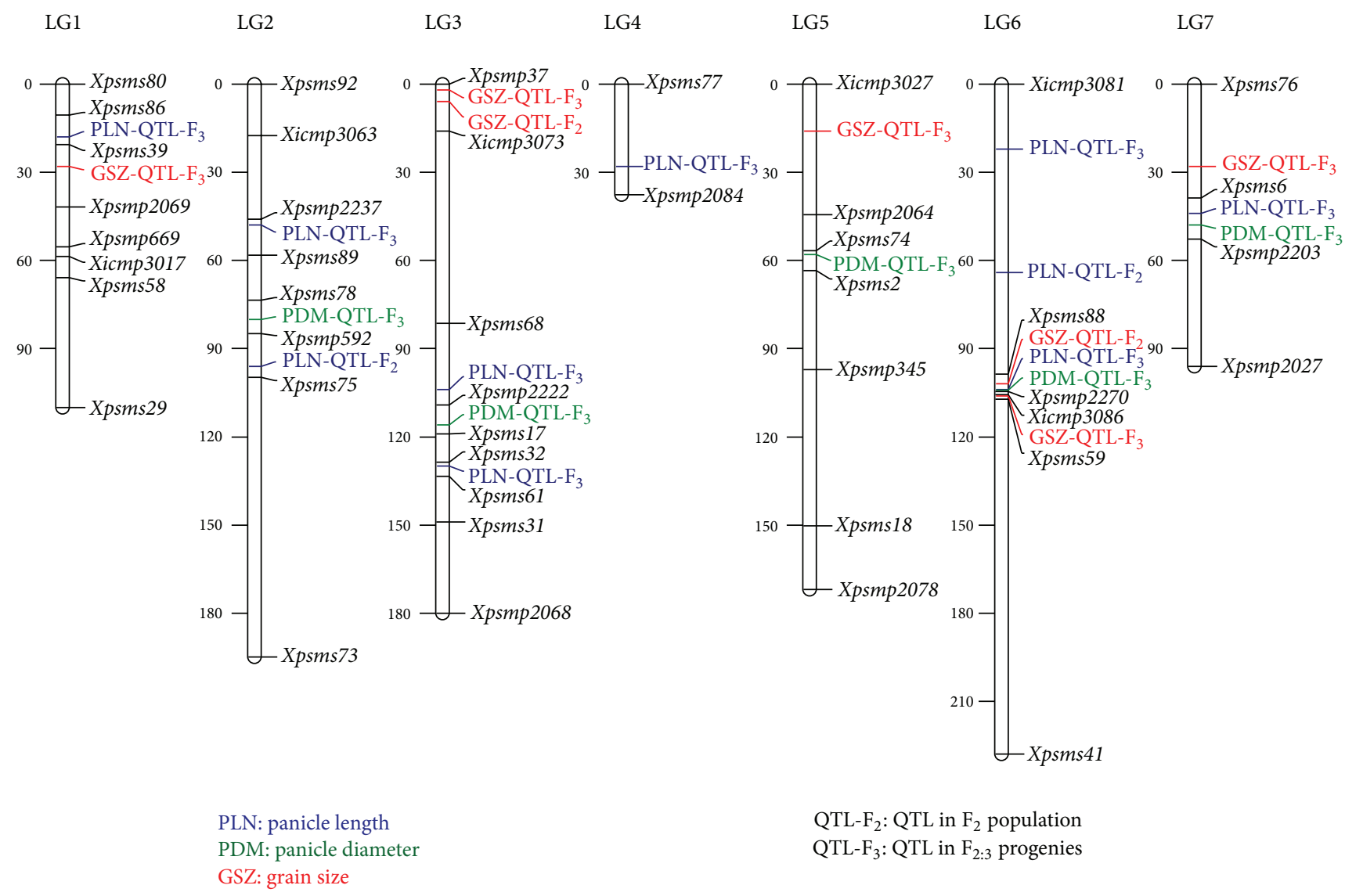

FIGURE 2: Pearl millet linkage map showing the position of detected QTLs across the $\mathrm{F}_{2}$ and $\mathrm{F}_{2: 3}$ mapping populations.

This may be due to the uncontrolled environmental influence on expression of the trait in unreplicated single plants. The QTLs identified using the replicated $\mathrm{F}_{2: 3}$ data set is more reliable as progeny means from replicated field plots were used as the unit of phenotypic measurement for QTL analysis [27].

3.3.3. Grain Size (1000-Grain Mass). QTLs identified for grain size using three genetic models are presented in Table 6. The additive model detected two QTLs for grain size using the $\mathrm{F}_{2: 3}$ data set. These mapped on LG1 and LG3 with LOD values of 2.8 and 3.1 and explained 6.4 and $10.4 \%$ of variation, respectively. This model also detected two QTLs using the $\mathrm{F}_{2}$ data set, one each on LG3 and LG6 with LOD values of 8.8 and 4.8, respectively, which explained 22.9 and $9.9 \%$ of observed variation. The favorable alleles for all of these QTLs were from $\mathrm{P}_{2}$. This model explained a total of $13.3 \%$ of observed variation for 1000-grain mass in the $\mathrm{F}_{2: 3}$ progenies and $32.2 \%$ of observed variation for this trait in the $\mathrm{F}_{2}$ population. The additive + dominance model detected five QTLs using the $\mathrm{F}_{2: 3}$ data set (LG1, LG3, LG5, LG6, and LG7) and the LOD scores for these QTLs ranged from 2.5 to 3.7 (Figure 2). The variation explained by additive effects of these QTLs ranged from 0.3 to $9.7 \%$, while dominance effects explained from 0.1 to $4.2 \%$. However, only two of these QTLs were detected for this trait using the $F_{2}$ data set. The QTLs on LG3 and LG6 had LOD scores of 9.4 and 6.6, additive effects explaining $24.0 \%$ and $13.2 \%$ and dominance effects explaining $2.3 \%$ and $3.9 \%$ of observed variation, respectively. The favorable alleles for all detected QTLs for this trait by this model were contributed by $\mathrm{P}_{2}$. The portion of observed variation explained by this model was $23.6 \%$ for the $\mathrm{F}_{2: 3}$ progenies and $35.6 \%$ for the $\mathrm{F}_{2}$ population. The epistatic model detected five significant pairwise interactions (three dominance $x$ dominance and two additive $\times$ dominance interactions) among the QTLs detected in the $\mathrm{F}_{2: 3}$ progenies. The variation explained by significant pairwise epistatic interactions ranged between $3.1 \%$ and $4.3 \%$. In the $\mathrm{F}_{2}$ population, a significant dominance $\times$ dominance interaction was observed between the two detected QTLs and this interaction explained 7.9\% of the observed variation for grain size. This model explained observed variation of $29.6 \%$ and $41.1 \%$ for the $\mathrm{F}_{2: 3}$ progenies and $\mathrm{F}_{2}$ population data sets, respectively. Interestingly, results from this epistatic model suggested that favorable alleles at the QTLs on LG5 and LG6 for this trait were contributed by $\mathrm{P}_{1}$ (and not $\mathrm{P}_{2}$ per the additive + dominance model) and that the two QTLs detected using the $\mathrm{F}_{2}$ data set (and that detected on LG1 using the $\mathrm{F}_{2: 3}$ data set) were recessively inherited.

In general, across the $\mathrm{F}_{2}$ and $\mathrm{F}_{2: 3}$ progeny populations using the three genetic models, a total of 5 QTLs were identified for grain size. These QTLs were distributed across LG1, LG3, LG5, LG6, and LG7. The QTLs on LG3 and 


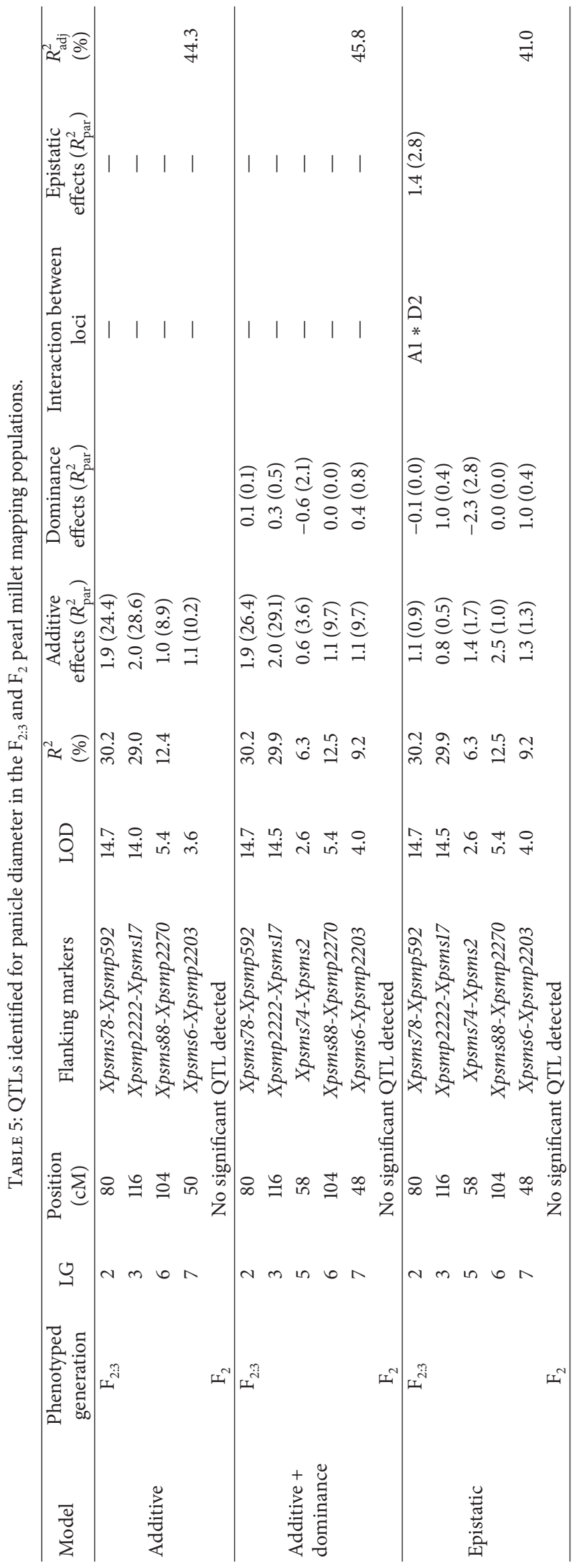




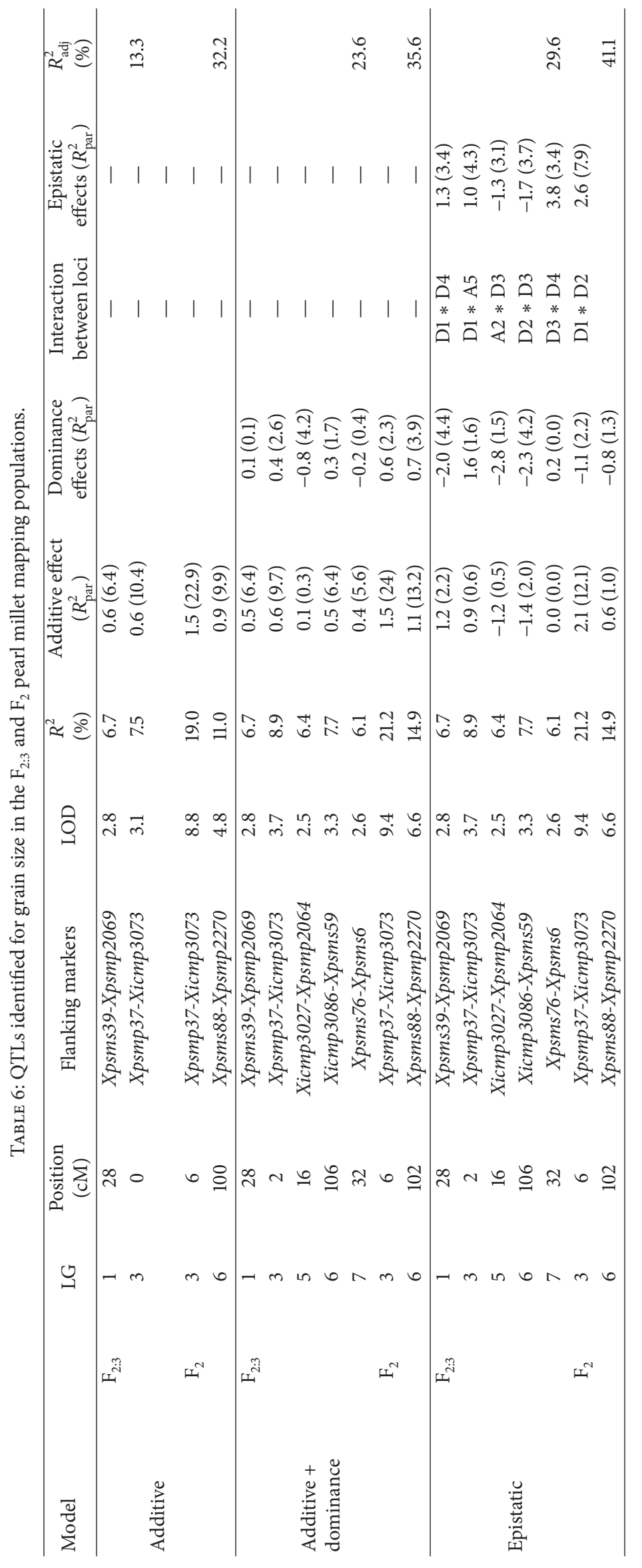


LG6 were detected in both $\mathrm{F}_{2}$ and $\mathrm{F}_{2: 3}$ data sets. Individual QTLs explained 6.1 to $21.2 \%$ of the observed phenotypic variation. The QTLs detected on LG1 and LG3 appear to be comparable to those reported by Bidinger et al. [6] and are entirely under additive control. The QTLs detected on LG6 and LG7 appear to be similar to those reported by Yadav et al. [16]. The present study also mapped an additional QTL for grain size on LG5, which has not been identified in earlier studies, and it contributed significantly to the total phenotypic variation observed for grain size. However, the position and relative values of dominance and additive effects for this putative QTL suggest that it may well be an artifact. The epistatic model detected significant interactions among all the detected QTLs. The observed variation for this trait was best explained by the epistatic model for both the $\mathrm{F}_{2: 3}$ progenies $(29.6 \%)$ and the $\mathrm{F}_{2}$ population $(41.4 \%)$. Significant epistatic interactions, additive $\times$ dominance, and dominance $\times$ dominance were observed among the detected QTLs, suggesting that the marginal effects of these QTLs could be biased. Epistatic model is necessary for validating the importance of the detected QTLs, and knowledge of the type of interactions provided can guide a researcher to choose appropriate genetic backgrounds of recipient lines in marker-assisted selection (MAS) to obtain maximal gains [58]. However, it is important that the genetic models accurately reflect the level of inbreeding of the progenies being phenotyped and genotyped to obtain reliable estimates of additive, dominance, and epistatic gene effects.

3.3.4. Comapped QTLs. Comapping of quantitative trait loci, identified for correlated traits, can be explained by both pleiotropism and linkage. However, it is not possible to distinguish between pleiotropy and linkage as a cause of such correlated effects until one has mapped the Quantitative Trait Nucleotide (QTN) responsible for phenotypic variation of each trait [59]. In the present study, genomic regions associated with panicle length, panicle diameter, and grain size were comapped to a small interval on LG6 between markers Xpsms88 and Xpsms2270. As expected, comapped QTLs for these traits also had significant correlations among them. Favorable alleles at the panicle length QTL were negatively associated with those for both panicle diameter and grain size. However, the favorable alleles for panicle diameter QTL showed positive associations with those for grain size, and favorable alleles for both traits were contributed from $\mathrm{P}_{2}$. It is possible to obtain favorable effects for several traits with alleles of one parent, such as the QTL for panicle diameter and grain size comapping on LG6, then these QTLs can become obvious targets for marker-assisted selection, provided that they are not also associated with unfavorable alleles for another important trait, in this case panicle length. There were additional QTLs for these traits that did not comap, and some of these with larger additive effects might be better targets for marker-assisted selection (e.g., the panicle length and panicle diameter QTLs on LG2, the peaks of which are separated by $30 \mathrm{cM}$ ). It is possible that there are a number of additional QTLs with small effects responsible for a large portion of variation that are common in those traits but could not be detected with the size of mapping population used and heritabilities achieved in the present study. The comapped QTLs demonstrated possibly the existence of genes or gene clusters with major effects that control significant proportions of the phenotypic variation in several quantitatively inherited traits related to sink size components. Further research is needed to distinguish between the pleiotropic effects of single genes and cluster of tightly linked genes affecting several traits.

\section{Conclusions}

The linkage map constructed primarily using SSCP-SNP markers is the first to be reported for pearl millet. It is hoped that this genetic map will prove useful in locating and manipulating genes of interest and in selection of yield-determining traits found linked with molecular markers in segregating populations. This study identified several QTLs that control the sink-size traits and confirmed the quantitative nature of their inheritance. These results are in agreement with the hypothesis that polygenes controlling important metric traits are distributed among several QTLs that need not be linked to one another [60]. The relatively high heritability estimates obtained suggest that selection for sink-size traits would be effective in early generations. However, it has also been noted that environmental factors may greatly influence variation in sink-size traits. Greater genetic gain is, therefore, more likely if selection is based on the genotype, as identified by QTL analysis, rather than the phenotype per se provided that the relevant multienvironment phenotyping data have been used to establish the marker-trait associations upon which genotype-based selection is to be undertaken. In the present study, the QTLs identified for panicle length on LG2 (LOD greater than 6 in the $\mathrm{F}_{2: 3}$ data set); for panicle diameter on LG2 and LG3 (LOD greater than 14 in the $\mathrm{F}_{2: 3}$ data set); and for grain size on LG3 and LG6 (LOD greater than 3 for both the $\mathrm{F}_{2}$ and $\mathrm{F}_{2: 3}$ data sets) provide nearly ideal targets for a marker-aided breeding strategy.

Putative epistatic interaction effects among the identified QTLs were also observed in this study. However, it is not clear that the effects detected were real or whether they were artifacts of applying the $F_{2}$ genetic model to a $F_{2: 3}$ phenotypic data set in which dominance effects observed were approximately half those expected in the $\mathrm{F}_{2}$ generation. This could be tested by (1) writing a more appropriate genetic model to fit to the $\mathrm{F}_{2: 3}$ phenotypic data and/or (2) by marker-assisted backcross introgression of possible allele combinations at two purportedly epistatic loci into a common genetic background and then assessing phenotypic differences between these near-isogenic introgression lines to see whether their performances fit model-predicted values. An accurate epistatic model is necessary for assessing the potential economic importance of QTLs detected. Knowledge of the type of interactions between alleles at various loci can guide a researcher to choose the most appropriate genetic backgrounds of recipient lines [58]. Several of the major QTLs identified in this study may be good sources of favorable 
alleles for marker-aided introgression into desirable genetic backgrounds, which could be a more effective approach for improving the sink-size component traits of pearl millet.

\section{Acknowledgments}

This paper is a part of a Ph.D. thesis of the senior author conducted at ICRISAT, Patancheru, Andhra Pradesh, and submitted to Tamil Nadu Agricultural University, Coimbatore, Tamil Nadu, India. The authors acknowledge the partial financial support from Pearl Millet Hybrid Parents Research Consortium and critical comments from Rajeev Varshney.

\section{References}

[1] L. N. Jindla and K. S. Gill, "Inter-relationship of yield and its component characters in pearl millet," Journal of Crop Improvement, vol. 11, no. 1, pp. 43-46, 1984.

[2] N. Maman, S. C. Mason, D. J. Lyon, and P. Dhungana, "Yield components of pearl millet and grain sorghum across environments in the central great plains," Crop Science, vol. 44, no. 6 , pp. 2138-2145, 2004.

[3] D. Yagya and C. R. Bainiwal, "Genetic analysis of crosses among pearl millet populations," International Sorghum and Millets Newsletter, vol. 42, pp. 68-70, 2001.

[4] F. H. Khadr and A. K. Qyinloye, "Mass selection for grain yield and seed size in pearl millet (Pennisetum typhoides)," Alexandria Journal of Agricultural Research, vol. 26, pp. 79-84, 1978.

[5] S. A. Quarrie, A. Steed, C. Calestani et al., "A high-density genetic map of hexaploid wheat (Triticum aestivum L.) from the cross Chinese Spring $\times$ SQ1 and its use to compare QTLs for grain yield across a range of environments," Theoretical and Applied Genetics, vol. 110, no. 5, pp. 865-880, 2005.

[6] F. R. Bidinger, T. Nepolean, C. T. Hash, R. S. Yadav, and C. J. Howarth, "Quantitative trait loci for grain yield in pearl millet under variable postflowering moisture conditions," Crop Science, vol. 47, no. 3, pp. 969-980, 2007.

[7] C. T. Hash, R. E. Schaffert, and J. M. Peacock, "Prospects for using conventional techniques and molecular biological tools to enhance performance of "orphan" crop plants on soils low in available phosphorus," Plant and Soil, vol. 245, no. 1, pp. 135-146, 2002.

[8] E. S. Jones, C. J. Liu, M. D. Gale, C. T. Hash, and J. R. Witcombe, "Mapping quantitative trait loci for downy mildew resistance in pearl millet," Theoretical and Applied Genetics, vol. 91, no. 3, pp. 448-456, 1995.

[9] R. N. Morgan, J. P. Wilson, W. W. Hanna, and P. Ozias-Akins, "Molecular markers for rust and pyricularia leaf spot disease resistance in pearl millet," Theoretical and Applied Genetics, vol. 96, no. 3-4, pp. 413-420, 1998.

[10] C. T. Hash and J. R. Witcombe, "Pearl millet molecular marker research," International Sorghum and Millets Newsletter, vol. 42, pp. 8-15, 2001.

[11] W. A. Breese, C. T. Hash, K. M. Devos, and C. J. Howarth, "Pearl millet genomics-an overview with respect to breeding for resistance to downy mildew," in Sorghum and Millets Pathology 2000, J. F. Leslie, Ed., pp. 243-246, Iowa State Press, Ames, Iowa, USA, 2002.

[12] E. S. Jonesa, W. A. Breeseb, C. J. Liuc, S. D. Singhd, D. S. Shawb, and J. R. Witcombe, "Mapping quantitative trait loci for resistance to downy mildew in pearl millet: field and glasshouse screens detect the same QTL," Crop Science, vol. 42, no. 4, pp. 1316-1323, 2002.

[13] C. T. Hash and J. R. Witcombe, "Gene management and breeding for downy mildew resistance," in Sorghum and Millets Pathology 2000, J. F. Leslie, Ed., pp. 27-36, Iowa State Press, Ames, Iowa, USA, 2002.

[14] S. K. Gulia, C. T. Hash, R. P. Thakur, W. A. Breese, and R. S. Sangwan, "Mapping new QTLs for downy mildew [Sclerospora graminicola (Sacc.) J. Schroet.] resistance in pearl millet (Pennisetum glaucum (L.) R. Br.)," in Crop Production in Stress Environments-Genetic and Management Options, S. P. Singh, V. S. Tomar, R. K. Behl, S. D. Upadhyaya, M. S. Bhale, and D. Khare, Eds., pp. 373-386, Agrobios Publishers, Jodhpur, India, 2007.

[15] C. J. Howarth, C. J. Pollock, and J. M. Peacock, "Development of laboratory-based methods for assessing seedling thermotolerance in pearl millet," New Phytologist, vol. 137, no. 1, pp. 129-139, 1997.

[16] R. S. Yadav, C. T. Hash, F. R. Bidinger, G. P. Cavan, and C. J. Howarth, "Quantitative trait loci associated with traits determining grain and stover yield in pearl millet under terminal drought-stress conditions," Theoretical and Applied Genetics, vol. 104, no. 1, pp. 67-83, 2002.

[17] F. R. Bidinger and C. T. Hash, "Pearl millet," in Physiology and Biotechnology Integration for Plant Breeding, H. T. Nguyen and A. Blum, Eds., pp. 225-270, Marcel Dekker, New York, NY, USA, 2004.

[18] R. S. Yadav, C. T. Hash, F. R. Bidinger, K. M. Devos, and C. J. Howarth, "Genomic regions associated with grain yield and aspects of post-flowering drought tolerance in pearl millet across stress environments and tester background," Euphytica, vol. 136, no. 3, pp. 265-277, 2004.

[19] P. Azhaguvel, C. T. Hash, P. Rangasamy, and A. Sharma, "Mapping the $d_{1}$ and $d_{2}$ dwarfing genes and the purple foliage color locus $P$ in pearl millet," Journal of Heredity, vol. 94, no. 2, pp. 155-159, 2003.

[20] R. S. Yadav, F. R. Bidinger, C. T. Hash et al., "Mapping and characterisation of QTL $\times$ E interactions for traits determining grain and stover yield in pearl millet," Theoretical and Applied Genetics, vol. 106, no. 3, pp. 512-520, 2003.

[21] C. T. Hash, M. D. A. Rahman, A. G. B. Raj, and E. Zerbini, "Molecular markers for improving nutritional quality of crop residues for ruminants," in Molecular Breeding of Forage Crops, G. Spangenberg, Ed., pp. 203-217, Kluwer Academic Publishers, Dordrecht, The Netherlands, 2001.

[22] C. T. Hash, A. G. Bhasker Raj, S. Lindup et al., "Opportunities for marker-assisted selection (MAS) to improve the feed quality of crop residues in pearl millet and sorghum," Field Crops Research, vol. 84, no. 1-2, pp. 79-88, 2003.

[23] T. Nepolean, M. Blümmel, A. G. Bhasker Raj, V. Rajaram, S. Senthilvel, and C. T. Hash, "QTLs controlling yield and stover quality traits in pearl millet," International Sorghum and Millets Newsletter, vol. 47, pp. 149-152, 2006.

[24] A. H. Paterson, "What has QTL mapping taught us about plant domestication?" New Phytologist, vol. 154, no. 3, pp. 591-608, 2002.

[25] E. S. Lander, P. Green, J. Abrahamson et al., "MAPMAKER: an interactive computer package for constructing primary genetic linkage maps of experimental and natural populations," Genomics, vol. 1, no. 2, pp. 174-181, 1987. 
[26] K. Mather and J. L. Jinks, Biometrical Genetics, Chapman and Hall, London, UK, 3rd edition, 1982.

[27] A. H. Paterson, "Comparative mapping of plant phenotypes," in Plant Breeding Reviews, vol. 14, pp. 13-37, John Wiley \& Sons, 1997.

[28] D. F. Austin and M. Lee, "Comparative mapping in $\mathrm{F}_{2: 3}$ and $\mathrm{F}_{6: 7}$ generations of quantitative trait loci for grain yield and yield components in maize," Theoretical and Applied Genetics, vol. 92, no. 7, pp. 817-826, 1996.

[29] T. Zhang, Y. Yuan, J. Yu, W. Guo, and R. J. Kohel, "Molecular tagging of a major QTL for fiber strength in Upland cotton and its marker-assisted selection," Theoretical and Applied Genetics, vol. 106, no. 2, pp. 262-268, 2003.

[30] C. J. Liu, J. R. Witcombe, T. S. Pittaway et al., "An RFLP-based genetic map of pearl millet (Pennisetum glaucum)," Theoretical and Applied Genetics, vol. 89, no. 4, pp. 481-487, 1994.

[31] V. Poncet, F. Lamy, K. M. Devos, M. D. Gale, A. Sarr, and T. Robert, "Genetic control of domestication traits in pearl millet (Pennisetum glaucum L., Poaceae)," Theoretical and Applied Genetics, vol. 100, no. 1, pp. 147-159, 2000.

[32] V. Poncet, E. Martel, S. Allouis et al., "Comparative analysis of QTLs affecting domestication traits between two domesticated $\times$ wild pearl millet (Pennisetum glaucum L., Poaceae) crosses," Theoretical and Applied Genetics, vol. 104, no. 6-7, pp. 965-975, 2002.

[33] K. M. Devos, T. S. Pittaway, A. Reynolds, and M. D. Gale, "Comparative mapping reveals a complex relationship between the pearl millet genome and those of foxtail millet and rice," Theoretical and Applied Genetics, vol. 100, no. 2, pp. 190-198, 2000.

[34] X. Qi, T. S. Pittaway, S. Lindup et al., "An integrated genetic map and a new set of simple sequence repeat markers for pearl millet, Pennisetum glaucum," Theoretical and Applied Genetics, vol. 109, no. 7, pp. 1485-1493, 2004.

[35] S. Senthilvel, B. Jayashree, V. Mahalakshmi et al., "Development and mapping of simple sequence repeat markers for pearl millet from data mining of expressed sequence tags," BMC Plant Biology, vol. 8, article 119, 2008.

[36] I. Eujayl, M. E. Sorrells, M. Baum, P. Wolters, and W. Powell, "Isolation of EST-derived microsatellite markers for genotyping the A and B genomes of wheat," Theoretical and Applied Genetics, vol. 104, no. 2-3, pp. 399-407, 2002.

[37] L. F. Gao, R. L. Jing, N. X. Huo et al., "One hundred and one new microsatellite loci derived from ESTs (EST-SSRs) in bread wheat," Theoretical and Applied Genetics, vol. 108, no. 7, pp. 1392$1400,2004$.

[38] J. K. Yu, T. M. Dake, S. Singh et al., "Development and mapping of EST-derived simple sequence repeat markers for hexaploid wheat," Genome, vol. 47, no. 5, pp. 805-818, 2004.

[39] I. Bertin, J. H. Zhu, and M. D. Gale, "SSCP-SNP in pearl milleta new marker system for comparative genetics," Theoretical and Applied Genetics, vol. 110, no. 8, pp. 1467-1472, 2005.

[40] F. A. Feltus, H. P. Singh, U. C. Lohithaswa, S. R. Schulze, T. D. Silva, and A. H. Paterson, "A comparative genomics strategy for targeted discovery of single-nucleotide polymorphisms and conserved-noncoding sequences in orphan crops," Plant Physiology, vol. 140, no. 4, pp. 1183-1191, 2006.

[41] E. S. Mace, H. K. Buhariwalla, and J. H. Crouch, "A highthroughput DNA extraction protocol for tropical molecular breeding programs," Plant Molecular Biology Reporter, vol. 21, no. 4, pp. 459-460, 2003.
[42] P. Martins-Lopes, H. Zhang, and R. Koebner, "Detection of single nucleotide mutations in wheat using single strand conformation polymorphism gels," Plant Molecular Biology Reporter, vol. 19, no. 2, pp. 159-162, 2001.

[43] B. J. Bassam, G. Caetano-Anolles, and P. M. Gresshoff, "Fast and sensitive silver staining of DNA in polyacrylamide gels," Analytical Biochemistry, vol. 196, no. 1, pp. 80-83, 1991.

[44] H. D. Patterson and R. Thompson, "Recovery of inter-block information when block sizes are unequal," Biometrika, vol. 58, no. 3, pp. 545-554, 1971.

[45] K. Mather and J. L. Jinks, Biometrical Genetics, Chapman and Hall, London, UK, 2nd edition, 1971.

[46] H. F. Utz and A. E. Melchinger, PLABQTL: A Computer Program to Map QTL, Version 1.0, University of Hohenheim, Stuttgart, Germany, 1995.

[47] Z. B. Zeng, "Precision mapping of quantitative trait loci," Genetics, vol. 136, no. 4, pp. 1457-1468, 1994.

[48] A. Rafalski, "Applications of single nucleotide polymorphisms in crop genetics," Current Opinion in Plant Biology, vol. 5, no. 2, pp. 94-100, 2002.

[49] M. S. Roder, J. Plaschke, S. U. Konig et al., "Abundance, variability and chromosomal location of microsatellites in wheat," Molecular and General Genetics, vol. 246, no. 3, pp. 327-333, 1995.

[50] T. A. Money, C. J. Liu, and M. D. Gale, "Conversion of RFLP markers for downy mildew resistance in pearl millet to sequence-tagged-sites," in Use of Molecular Markers in Sorghum and Pearl Millet Breeding for Developing Countries, Proceedings of an ODA Plant Sciences Research Programme Conference, 29th March-1st April, 1993, pp. 65-68, Norwich, UK, 1993.

[51] S. Kicherer, G. Backes, U. Walther, and A. Jahoor, "Localising QTLs for leaf rust resistance and agronomic traits in barley (Hordeum vulgate L.)," Theoretical and Applied Genetics, vol. 100, no. 6, pp. 881-888, 2000.

[52] W. D. Beavis, "QTL analyses: power, precision, and accuracy," in Molecular Analysis of Complex Traits, A. H. Paterson, Ed., pp. 145-162, CRC Press, Cleveland, Ohio, USA, 1998.

[53] C. Vogl and S. Xu, "Multipoint mapping of viability and segregation distorting loci using molecular markers," Genetics, vol. 155, no. 3, pp. 1439-1447, 2000.

[54] J. M. Sandbrink, J. van Ooijen, C. C. Purimahua et al., "Localization of genes for bacterial canker resistance in Lycopersicon peruvianum using RFLPs," Theoretical and Applied Genetics, vol. 90, no. 3-4, pp. 444-450, 1995.

[55] D.-H. He, Z. X. Lin, X. L. Zhang et al., "Mapping QTLs of traits contributing to yield and analysis of genetic effects in tetraploid cotton," Euphytica, vol. 144, no. 1-2, pp. 141-149, 2005.

[56] M. J. Kearsey and A. G. L. Farquhar, "QTL analysis in plants; where are we now?” Heredity, vol. 80, no. 2, pp. 137-142, 1998.

[57] D. S. Falconer, Introduction to Quantitative Genetics, Longman, London, UK, 3rd edition, 1989.

[58] Ö. Carlborg and C. S. Haley, "Epistasis: too often neglected in complex trait studies?" Nature Reviews Genetics, vol. 5, no. 8, pp. 618-625, 2004

[59] T. F. C. Mackay, "The genetic architecture of quantitative traits," Annual Review of Genetics, vol. 35, pp. 303-339, 2001.

[60] C. A. Fatokun, D. I. Menancio-Hautea, D. Danesh, and N. D. Young, "Evidence for orthologous seed weight genes in cowpea and mung bean based on RFLP mapping," Genetics, vol. 132, no. 3, pp. 841-846, 1992. 

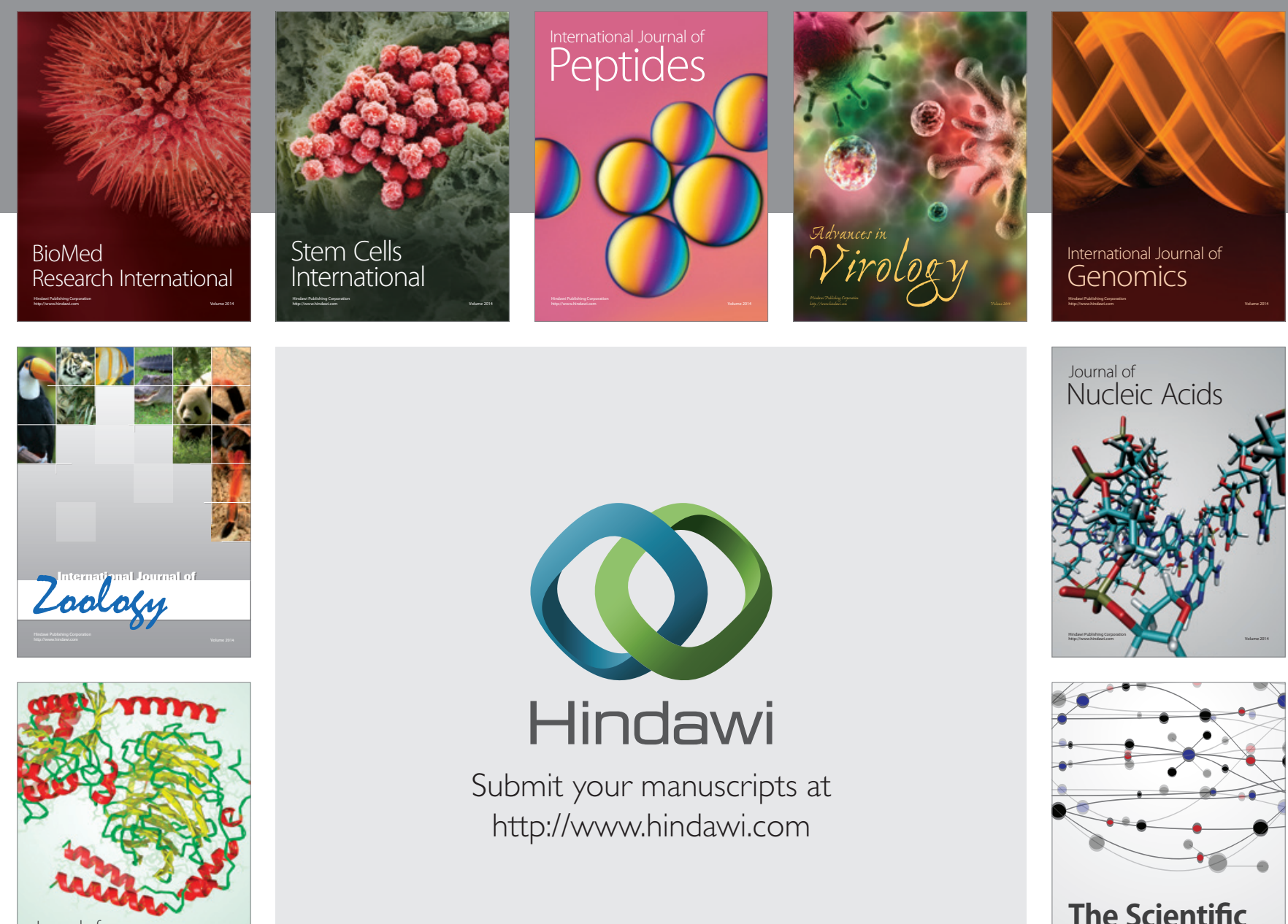

Submit your manuscripts at

http://www.hindawi.com

Journal of
Signal Transduction
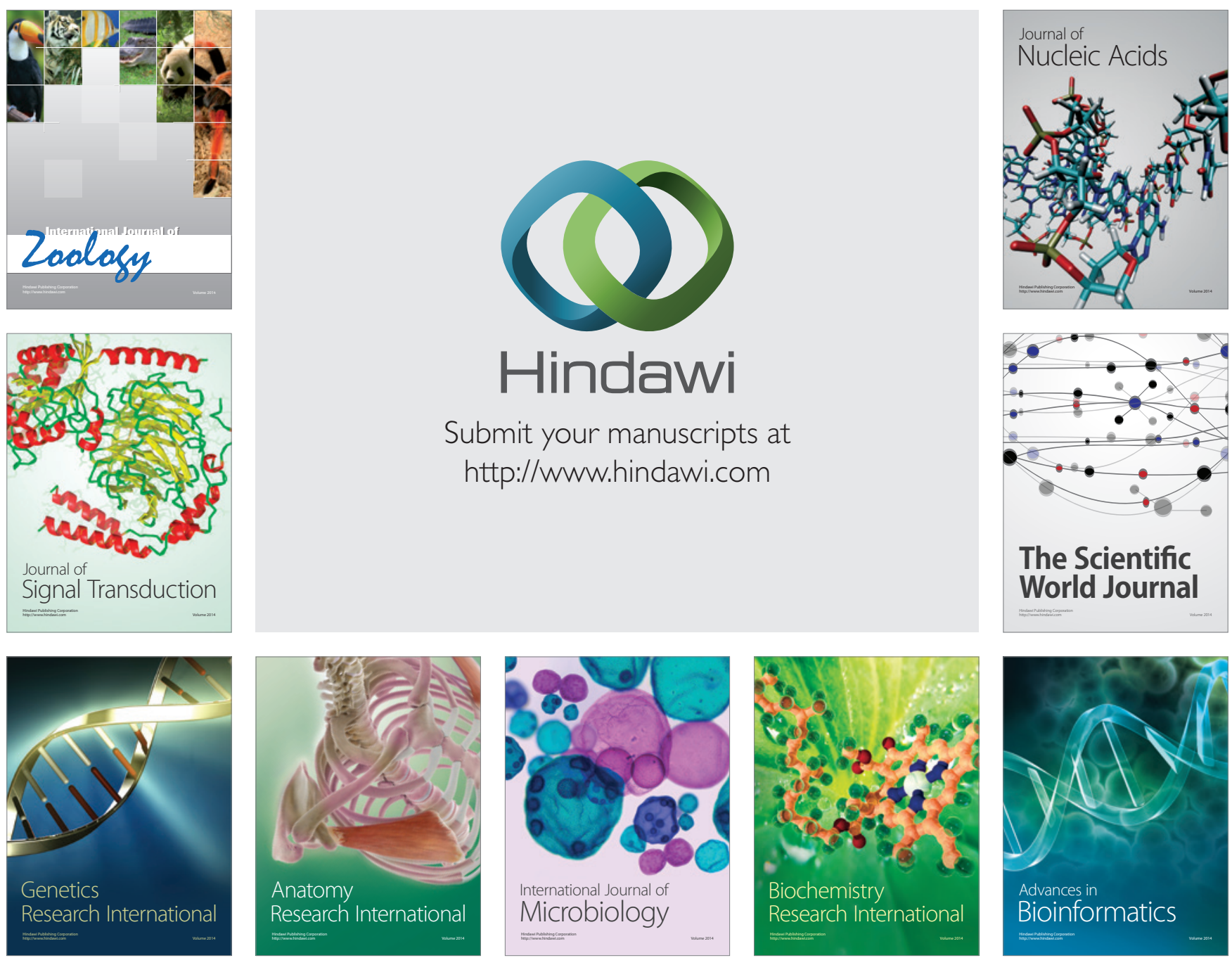

The Scientific World Journal
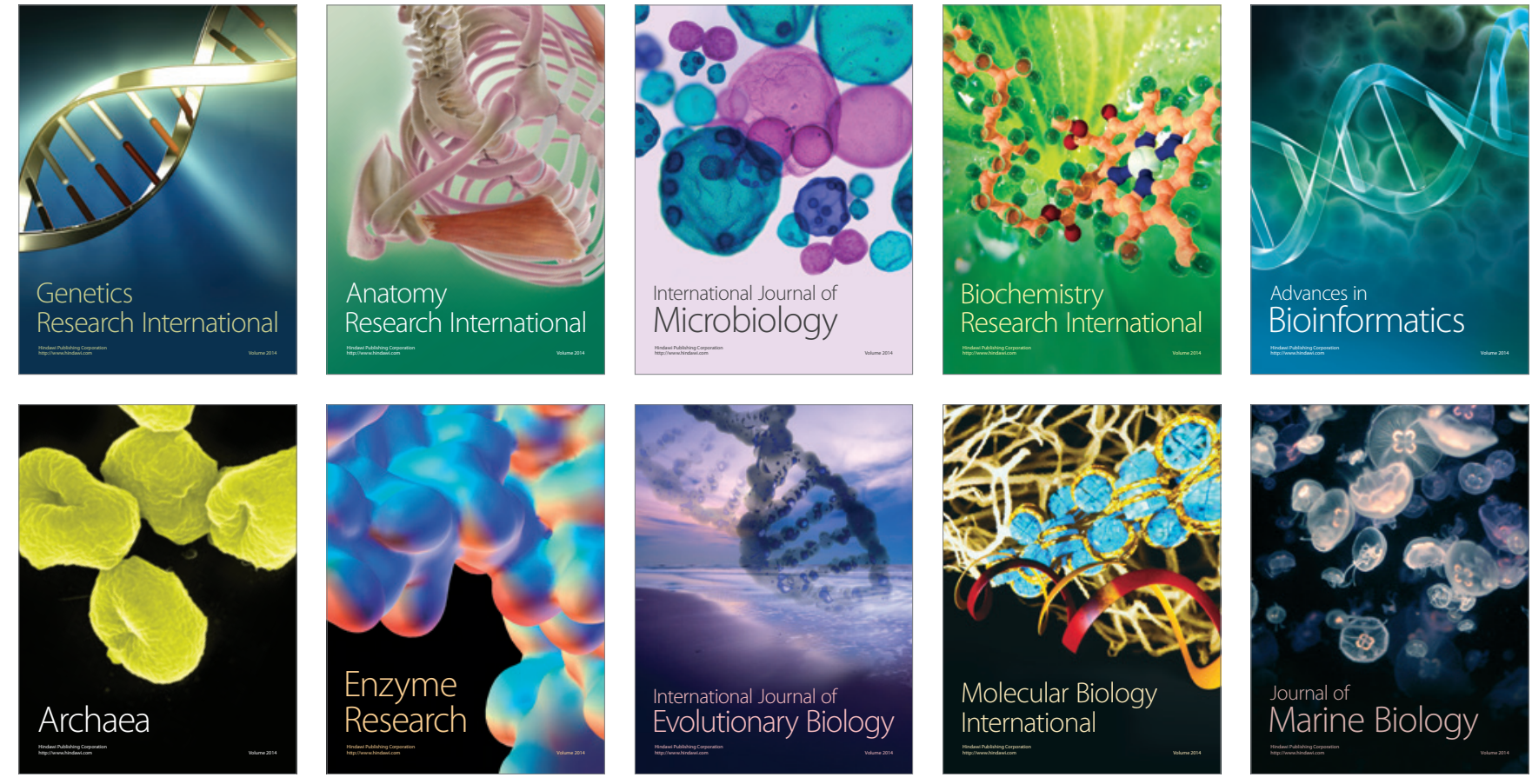